\title{
Highly Efficient Organic UV Photodetectors Based on Polyfluorene and Naphthalenediimide Blends: Effect of Thermal Annealing
}

\author{
Gorkem Memisoglu and Canan Varlikli \\ Solar Energy Institute, Ege University, Izmir, 35100 Bornova, Turkey \\ Correspondence should be addressed to Canan Varlikli, canan.varlikli@ege.edu.tr \\ Received 28 October 2011; Accepted 17 January 2012 \\ Academic Editor: Xie Quan
}

Copyright (C) 2012 G. Memisoglu and C. Varlikli. This is an open access article distributed under the Creative Commons Attribution License, which permits unrestricted use, distribution, and reproduction in any medium, provided the original work is properly cited.

A solution-processed organic ultraviolet photodetector (UV-PD) is introduced. The active layer of the UV-PD consists of poly(9,9dioctyl fluorenyl-2,7-yleneethynylene) (PFE) and $N, N^{\prime}$-bis- $n$-butyl-1,4,5,8- naphthalenediimide (BNDI) with a weight ratio of $3: 1$ in chloroform. The effect of thermal annealing on the device properties was investigated from room temperature to $80^{\circ} \mathrm{C}$. The full device structure of ITO/PEDOT:PSS/PFE:BNDI $(3: 1) / \mathrm{Al}$ gave responsivity of $410 \mathrm{~mA} / \mathrm{W}$ at $-4 \mathrm{~V}$ under $1 \mathrm{~mW} / \mathrm{cm}^{2} \mathrm{UV}$ light at $368 \mathrm{~nm}$ when $60^{\circ} \mathrm{C}$ of annealing temperature was used during its preparation. The devices that were annealed over the crystallization temperature of PFE showed a charge transfer resistance increase and a mobility decrease.

\section{Introduction}

Ultraviolet (UV) photodetectors absorb UV light energy and convert it into electrical response that can be measured. Detection of UV is necessary for many sectors such as medical, military, and space research, and so forth [1-3]. Although inorganic semiconductor-based UV detectors provide many advantages, their manufacturing is expensive and complicated. Recently, organic semiconductor-based UV photodetectors have attracted much attention due to their low cost and easy processability of the used materials (Table 1) [4-16]. Strong absorption ability, high charge carrier mobility, and energy level convenience of donor and acceptor materials are important while using organic semiconductors as active layers in a UV photodetector.

Naphthalenediimide (NDI) derivatives are known to have UV absorption between the wavelengths of 300$400 \mathrm{~nm}$ with molar extinction coefficients of around $1-5 \times$ $10^{4} \mathrm{M}^{-1} \mathrm{~cm}^{-1}$ in solution phase [16]. Additionally, because their tendency to aggregate is relatively low, the absorption characteristics are almost the same in their solution and film phases [17]. NDI derivatives have high electron mobility (up to $\left.10^{-2} \mathrm{~cm}^{2} / \mathrm{Vs}\right)[18,19]$ and therefore find application in many different kinds of photochemical molecular devices like, solar cells, organic field effect transistors, and so forth [7, 19-21]. Polyfluorenes (PFs) are p-type semiconductors with a hole mobility of around $10^{-3}-10^{-4} \mathrm{~cm}^{2} / \mathrm{Vs}$ at room temperature [22, 23]. The highest occupied molecular orbital (HOMO) and lowest unoccupied molecular orbital (LUMO) energy levels of NDI and PF derivatives are suitable to form a donor (PF)-acceptor (NDI) couple. Recently, Li et al. have reported a PF-and NDI-based organic UV photodetector with a device structure of ITO/PP/PFH:NDI-BA(1:1)/Al and a responsivity value of $224 \mathrm{~mA} / \mathrm{W}$ at $-4 \mathrm{~V}$ under $1 \mathrm{~mW} /$ $\mathrm{cm}^{2}$ [7]. As it can be noticed from Table 1 the responsivity values obtained by the use of PF derivatives and their NDI blends represent one of the best results.

In addition to the nature of materials that are used, vacuum levels used during the metal evaporation and annealing temperature are the other two important issues to control for obtaining high device performances. High vacuum levels may increase inductive effects [24] and consequently reduce device performance. Regarding the annealing temperature, although there are many studies on its positive effects [7, 23$25]$, a few report that annealing may have no effect at all [8]. 
TABLE 1: Properties of organic semiconductor-based photodetectors already published in the literature.

\begin{tabular}{|c|c|c|c|c|c|}
\hline $\begin{array}{l}\text { Reference } \\
\text { number }\end{array}$ & Device structure & $\begin{array}{l}\text { Active area } \\
\left(\mathrm{mm}^{2}\right)\end{array}$ & $\begin{array}{c}J\left(\mathrm{~mA} / \mathrm{cm}^{2}\right) ; \\
V_{\mathrm{appl}}\end{array}$ & $\begin{array}{c}\text { otocurrent } \\
\text { response }(\mathrm{mA} / \mathrm{W}) \\
V_{\mathrm{appl}}\end{array}$ & $\begin{array}{c}\text { UV intensity } \\
\left(\mathrm{mW} / \mathrm{cm}^{2}\right) ; \lambda(\mathrm{nm})\end{array}$ \\
\hline \multirow[t]{2}{*}[4]{} & ITO/F8T2 : PCBM/Au & 0.03 & $\sim 9 ;-14 \mathrm{~V}$ & NA & $9 ; 460 \mathrm{~nm}$ \\
\hline & $\mathrm{ITO} / \mathrm{TsAF} / \mathrm{Au}$ & 0.01 & $\sim 17 ;-13 \mathrm{~V}$ & NA & $8 ; 460 \mathrm{~nm}$ \\
\hline \multirow{3}{*}[5]{} & ITO/TPD : $\mathrm{Alq}_{3} / \mathrm{Al}$ & NA & $0.108 ;-8 \mathrm{~V}$ & $90 ;-8 \mathrm{~V}$ & $1.2 ; 365 \mathrm{~nm}$ \\
\hline & ITO/m-MTDATA : $\mathrm{Alq}_{3} / \mathrm{Al}$ & NA & $0.359 ;-8 \mathrm{~V}$ & $299 ;-8 \mathrm{~V}$ & $1.2 ; 365 \mathrm{~nm}$ \\
\hline & ITO/m-MTDATA : $\mathrm{Gaq}_{3} / \mathrm{Al}$ & NA & $0.405 ;-8 \mathrm{~V}$ & $338 ;-8 \mathrm{~V}$ & $1.2 ; 365 \mathrm{~nm}$ \\
\hline$[6]$ & ITO/mMTDATA/mMTDATA : TPBi/TPBi/BCP/LiF/Al & NA & $0.0467 ; 0 \mathrm{~V}$ & $135 ;-4 \mathrm{~V}$ & $0.426 ; 365 \mathrm{~nm}$ \\
\hline$[7]$ & ITO/PEDOT : PSS/PFH : NDI-BA/Al & NA & $226 ;-4 \mathrm{~V}$ & $224 ;-4 \mathrm{~V}$ & $1 ; 365 \mathrm{~nm}$ \\
\hline$[8]$ & ITO/PEDOT $:$ PSS/ $\mathrm{TiO}_{2}-\mathrm{PFH} / \mathrm{Al}$ & 7.5 & NA & $6.92 ; 0 \mathrm{~V}$ & $3.6 ; 365 \mathrm{~nm}$ \\
\hline \multirow[t]{2}{*}[9]{} & ITO/PEDOT : PSS/b-TiO $2 / \mathrm{PFH} / \mathrm{Al}$ & 7.5 & $0.091 ; 0 \mathrm{~V}$ & $28.4 ; 0 \mathrm{~V}$ & 3.2 \\
\hline & ITO/PEDOT : PSS/OA-TiO 2 : PFH/Al & 7.5 & $0.019 ; 0 \mathrm{~V}$ & $5.9 ; 0 \mathrm{~V}$ & $3.2 ; 365 \mathrm{~nm}$ \\
\hline$[10]$ & $\mathrm{ITO} / \mathrm{F}_{4} \mathrm{TCNQ} / \mathrm{TPD} / \mathrm{P} 2 \mathrm{NHC} / \mathrm{BCP} / \mathrm{LiF} / \mathrm{Al}$ & 2 & NA & $77 ;-16 \mathrm{~V}$ & $390 \mathrm{~nm}$ \\
\hline$[11]$ & ITO/PEDOT: PSS/CFC: $\mathrm{ZnO} / \mathrm{Al}$ & 9 & $0.046 ;-2 \mathrm{~V}$ & $46 ;-2 \mathrm{~V}$ & $1 ; 365 \mathrm{~nm}$ \\
\hline$[12]$ & ITO/m-MTDATA/TPBi/Al & 6 & $0.0681 ;-6.5 \mathrm{~V}$ & $75.2 ;-6.5 \mathrm{~V}$ & $1 ; 365 \mathrm{~nm}$ \\
\hline$[13]$ & ITO/ZnO/PVK/PEDOT $:$ PSS/Au & NA & $0.132 ;-5 \mathrm{~V}$ & $110 ;-5 \mathrm{~V}$ & $1.2 ; 365 \mathrm{~nm}$ \\
\hline$[14]$ & $\mathrm{FTO} / \mathrm{TiO}_{2} / \mathrm{PFH} / \mathrm{Au}$ & 3 & $0.0038 ; 10 \mathrm{~V}$ & NA & 3.2 \\
\hline [15] & ITO/PEDOT: PSS/PFP/NSN/LiF/Al & NA & $0.697 ;-12 \mathrm{~V}$ & $696 ;-12 \mathrm{~V}$ & $1 ; 365 \mathrm{~nm}$ \\
\hline$[16]$ & ITO/m-MTDATA :/LiF/Al & NA & $0.276 ;-7.5 \mathrm{~V}$ & $230 ;-7.5 \mathrm{~V}$ & $1.2 ; 365 \mathrm{~nm}$ \\
\hline
\end{tabular}

In this study, with the motivation to increase UV photodetector responsivity of PF:NDI blends, we have studied the photoluminescence properties of poly $(9,9$-dioctyl fluorenyl-2,7-yleneethynylene) (PFE): $N, N^{\prime}$-bis- $N$-( $n$-butyl)1,4,5,8-naphthalenediimide (BNDI) blends, prepared the photodetector of optimized PFE:BNDI ratio, and investigated the effect of thermal annealing on responsivity by the use of steady-state photoluminescence spectroscopy, current density-voltage characteristics, and impedance spectroscopy, respectively. The device structure of ITO/PEDOT: $\mathrm{PSS} /(\mathrm{PFE}: \mathrm{BNDI})(3: 1) / \mathrm{Al}$ annealed at $60^{\circ} \mathrm{C}$ gave a responsivity of $410 \mathrm{~mA} / \mathrm{W}$ at $-4 \mathrm{~V}$ under $1 \mathrm{~mW} / \mathrm{cm}^{2} \mathrm{UV}$ light $(368 \mathrm{~nm})$.

\section{Experimental}

2.1. Materials. Indium-tin-oxide-(ITO-) coated glass substrates were obtained from the Delta Technologies with a sheet resistance of $4-10 \Omega / \square$. Glass slides (lams) were obtained from ISOLAB. Poly(3,4-ethylenedioxy thiophene):poly(styrene sulfonate) (PEDOT:PSS), poly(9,9-dioctyl fluorenyl-2,7-yleneethynylene) (PFE), aluminum (Al), ferrocene $(\mathrm{Fc})$, and tetrabutylammonium hexafluorophosphate $\left(\mathrm{TBAPF}_{6}\right)$ were purchased from Sigma Aldrich. All the other chemicals used were in analytical grade and used as received.

The chemical structures of the materials are given in Figure 1.

2.2. Instrumentation. Electrochemical characterization of PFE was performed by using $\mathrm{CH}$ Instruments $660 \mathrm{~B}$ Model workstation with a scan rate of $100 \mathrm{mV} / \mathrm{s}$. Thermal characteristics were investigated by Perkin Elmer Pyris6 Differential Scanning Calorimeter (DSC) with a heating rate of $20^{\circ} \mathrm{C} / \mathrm{min}$ from $0^{\circ} \mathrm{C}$ to $250^{\circ} \mathrm{C}$. Absorption and photoluminescence spectra of thin films were obtained with Analytic Jena S600 UV and PTI-QM1 Fluorescence Spectrophotometers, respectively. Laurell WS-400B-6NPP-LITE spin coater was used for the preparation of organic coatings. Thicknesses and morphologies of the films were measured by Ambios XP-1 high-resolution surface profiler and Ambios QScope 250 model atomic force microscope (AFM). Current-voltage (I-V) characteristics of the photodetectors were obtained with Keithley 2400 source meter under dark and different illumination intensities. Illumination was provided from a solar simulator with an EPS module (K. H. Steuernagel Lichttechnik Gmbh) and controlled by Nova II Versatile Laser Power/Energy Displayer. Photocurrent response of devices was measured by a SpectraPro 2300i Princeton Instruments $0.3 \mathrm{~m}$ Imaging Triple Grating Monochromator/Spectrograph equipped with the source meter. IM6 Zahner Elektrik impedance analyzer was used for impedance studies, and equivalent circuit model was obtained by the SIM program. All of the electrical measurements were performed under ambient atmospheric conditions without encapsulation.

2.3. Synthesis of $N, N^{\prime}$-Bis-N-(n-butyl)-1,4,5,8-naphthalenediimide (BNDI). BNDI was synthesized according to the literature [20]. ${ }^{1} \mathrm{H}-\mathrm{NMR}\left(\delta_{\mathrm{H}}, \mathrm{ppm}, 400 \mathrm{MHz}, \mathrm{CDCl}_{3}\right): 8.73$ $(s, 4 \mathrm{H}) ; 4.21-4.17(t, 4 \mathrm{H}) ; 1.76-1.68(m, 4 \mathrm{H}) ; 1.50-1.40$ $(m, 4 \mathrm{H}) ; 1.00-0.95(t, 6 \mathrm{H}) .{ }^{13} \mathrm{C}-\mathrm{NMR}\left(\delta_{\mathrm{C}}, \mathrm{ppm}, 100 \mathrm{MHz}\right.$, $\left.\mathrm{CDCl}_{3}\right): 163.03,131.11,126.87,126.83,40.95,30.49,20.79$, 14.14 . 

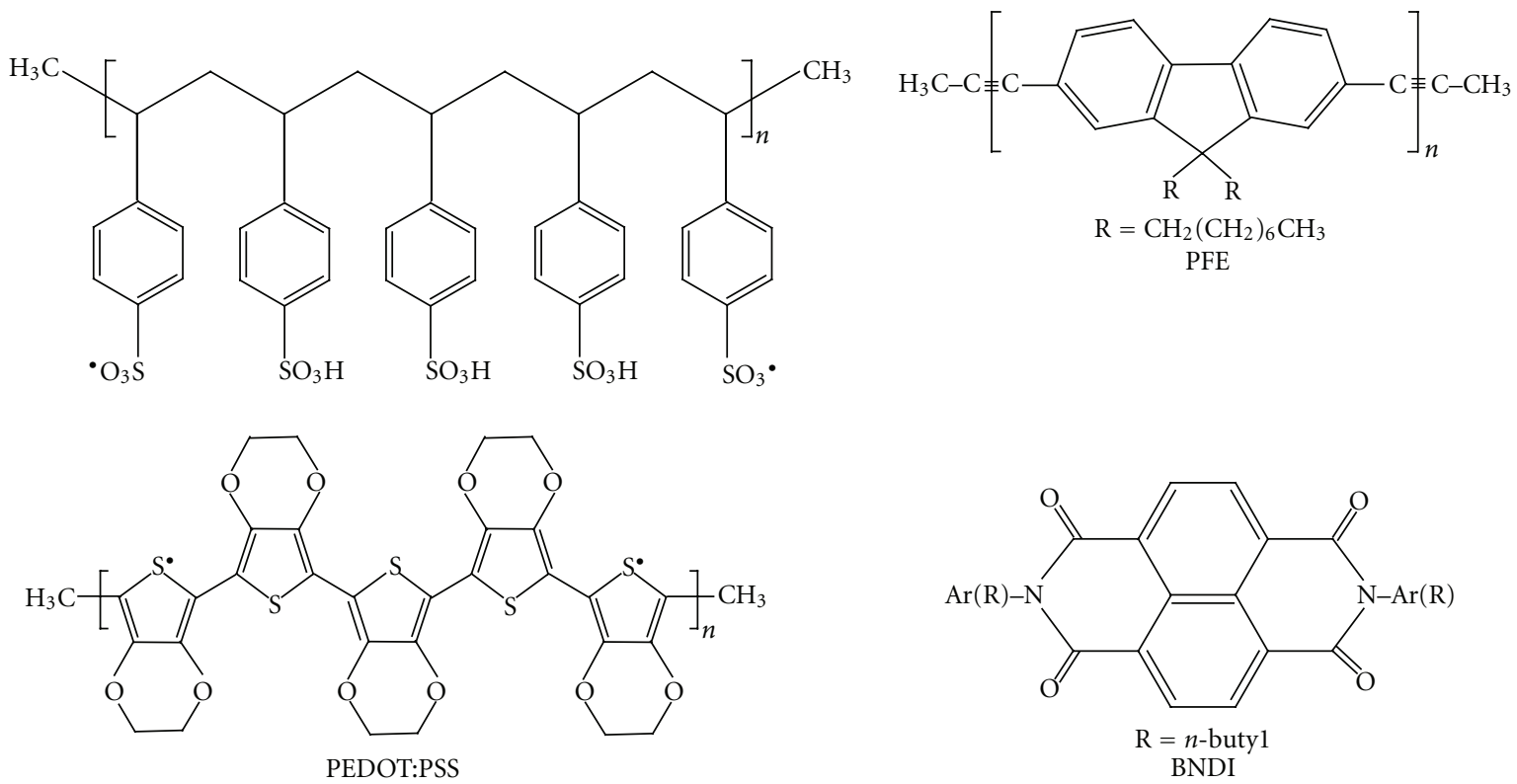

PFE

Figure 1: Chemical structures of PEDOT:PSS, PFE, and BNDI.

2.4. Sample Preparation for Optical Investigation. Lams were ultrasonically cleaned in detergent solution, deionized water, and acetone for $15 \mathrm{~min}$. each and blow-dried with nitrogen gun. Before coating the organic layers, they were treated with $\mathrm{O}_{2}$ plasma for $2 \mathrm{~min}$. Different weight ratios of PFE and BNDI blends were spin-coated at $1500 \mathrm{rpm}$ from a total dye concentration of $10 \mathrm{mg} / \mathrm{mL}$ in chloroform.

2.5. Device Preparation for Electrical Investigation. ITO glass substrates were etched, and above-described cleaning steps are applied. After the cleaning process, PEDOT:PSS was spincoated at $3000 \mathrm{rpm}$ for $1 \mathrm{~min}$. and dried in a vacuum oven at $100^{\circ} \mathrm{C}$ for $30 \mathrm{~min}$. which yielded a $45 \mathrm{~nm}$ film thickness. Organic semiconductor layer of PFE:BNDI $(1: 1 ; 1: 2 ; 1: 3$; $1: 4 ; 1: 5 ; 2: 1 ; 3: 1 ; 4: 1 ; 5: 1$ by weight) blends with a total dye concentration of $10 \mathrm{mg} / \mathrm{mL}$ in chloroform was spin-coated at $1500 \mathrm{rpm}$ for $1 \mathrm{~min}$ on PEDOT:PSS-coated ITO glass. Then, the spin-coated samples were annealed at $40^{\circ} \mathrm{C}, 60^{\circ} \mathrm{C}$, and $80^{\circ} \mathrm{C}$ for 15 minutes in vacuum oven. The composition of the blend and annealing temperature did not cause a significant difference in the film thickness. They were all around $90 \mathrm{~nm}$. Al cathode was deposited through a shadow mask by the use of a vacuum evaporator, attached to a MBRAUN 200B glove box system, at a rate of $0.3 \AA / \mathrm{s}$ and at low pressure $\left(1 \times 10^{-4} \mathrm{~Pa}\right)$ to minimize the negative effects [24]. The active area of photodetectors was $12 \mathrm{~mm}^{2}$, and five parallel measurements were performed for each device.

\section{Results and Analysis}

3.1. Electrochemical and Thermal Investigation. Electrochemical investigation of PFE was performed by using glassy carbon as working, Pt wire as counter, and Ag wire as reference electrodes. The supporting electrolyte was $0.1 \mathrm{M}$
$\mathrm{TBAPF}_{6}$ in chloroform, and $\mathrm{Fc}$ was used as the internal standard $\left(E^{o}{ }_{\left(F_{c} / F_{c+}\right)}=0.27 \mathrm{~V}\right.$ versus $\mathrm{Ag}$ in chloroform). The onset potential of the first oxidation peak $(1.08 \mathrm{~V})$ was used to determine the HOMO energy level [26] and calculated to be $-5.6 \mathrm{eV}$. The optical band gap $\left(\Delta E_{g}\right)$ obtained from the onset of absorption spectrum of PFE is $3.2 \mathrm{eV}$. Therefore, the addition of HOMO energy level and $\Delta E_{g}$ resulted in LUMO energy level of PFE, that is, $-2.4 \mathrm{eV}$. The values of HOMO and LUMO energy levels of BNDI were taken from the literature [19]. Cyclic voltammogram of PFE is presented in Figure 2 together with the energy level diagram of the photodetector.

Although both PFE and BNDI are known structures from the literature, we could reach no data regarding their thermal properties which is important while monitoring the thermal annealing effects on a photochemical molecular device performance $[7,8,23-25]$. DSC curves of PFE and NDI gave crystallization peaks at $75^{\circ} \mathrm{C}$ and $130^{\circ} \mathrm{C}$, respectively, and no glass transition temperature could be detected. Therefore, annealing experiments are performed from room temperature (RT) to $80^{\circ} \mathrm{C}$.

3.2. Photophysics of PFE:BNDI Blends. As it can be seen from Figure 3, the absorption wavelength regions of PFE and BNDI films overlap. However when the energy levels of HOMO and LUMO are considered (Figure 2), these two materials may go into a donor-acceptor relationship that would result in the quenching of PFE emission. Therefore, first of all the change in ground-state absorption and emission characteristics of PFE by the addition of BNDI is investigated. It is observed that the increase in BNDI weight ratio causes a decrease in $\pi-\pi^{*}$ absorption intensity of PFE at $410 \mathrm{~nm}$ (Figure $4(\mathrm{a})$ ) and quenches its emission (Figure $4(\mathrm{~b}))\left(\lambda_{\text {ext }}=368 \mathrm{~nm}\right)$. Although a decrease in emission 


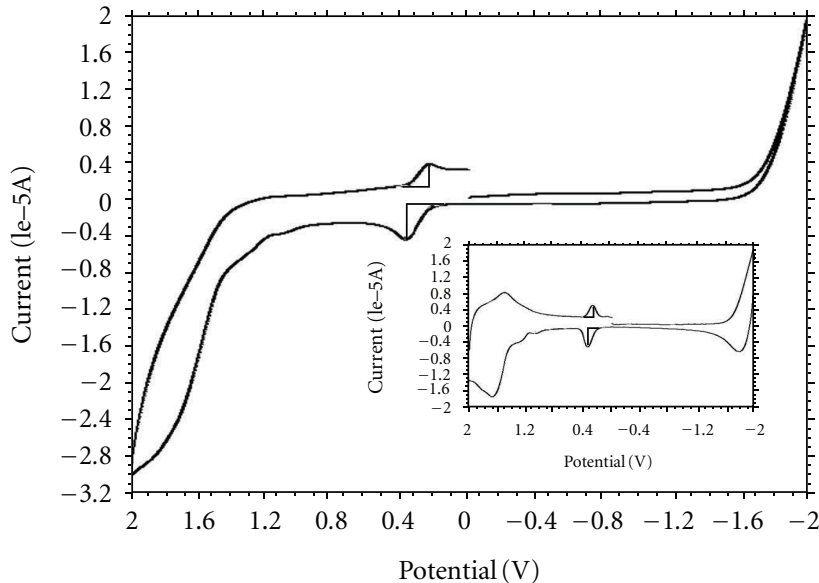

(a)

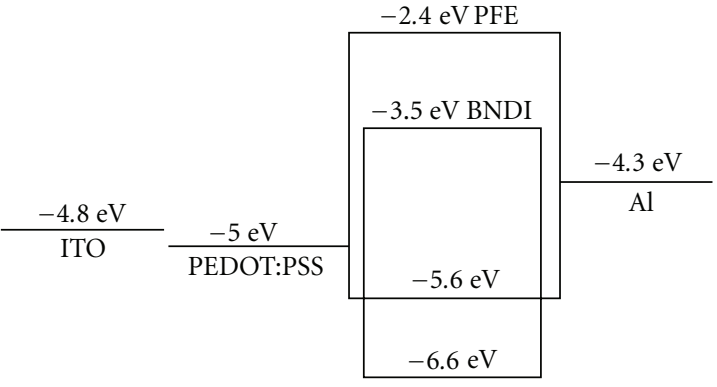

(b)

FIgure 2: (a) Cyclic voltammogram of PFE in chloroform (inset: derivative of cyclic voltammogram) and (b) energy level diagram of the photodetector.

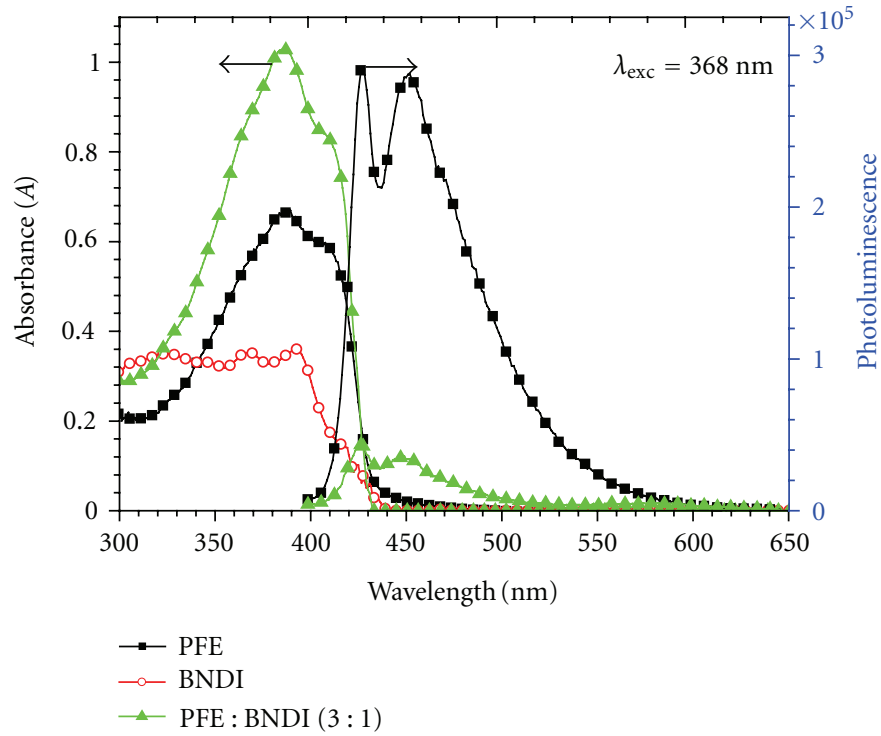

(a)

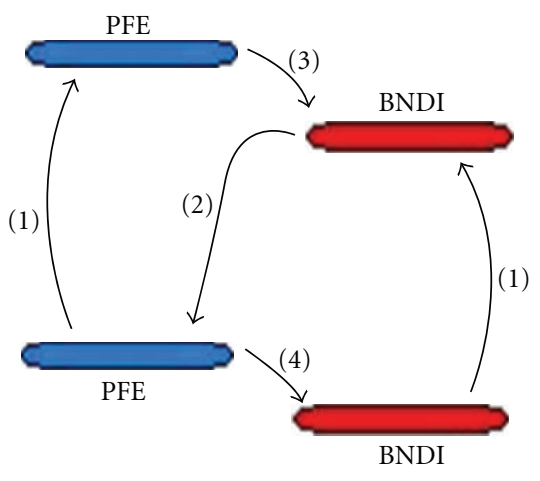

(1) Excitation of PFE and BNDI

(2) Nonradiative energy transfer

(3) Excited-state electron transfer

(4) Ground-state electron transfer

(b)

FIGURE 3: Absorption and photoluminescence spectra of (a) neat PFE and PFE:BNDI (3:1) and absorption spectrum of BNDI films and (b) proposed mechanism for the relationship between PFE and BNDI.

intensity that accompanies an increase in absorption is gained from PFE:BNDI blend with the $1: 2$ weight ratio, the magnitude of emission quenching is not good enough for a photodetector application. Additionally, when the 10to 100 - fold difference between the electron mobility of NDI and hole mobility of PF derivatives [18, 19, 22, 23] is considered, increasing the weight ratio of PFE in the blend becomes essential.

The absorption and emission spectra obtained from PFE:BNDI (1-5:1) blends are given in Figures 4(c) and 4(d). The quenching of emission is almost completed in $3: 1$ weight ratio of PFE:BNDI blend that also has the maximum absorption intensity. The proposed mechanism for the relationship between PFE and BNDI contains (1) excitation of both PFE and BNDI at $368 \mathrm{~nm}$, (2) nonradiative transfer from the LUMO of BNDI to the ground state of PFE, and (3) transfer of excited-state electrons of PFE to the LUMO level of BNDI. Further increase of PFE weight ratio in blend caused a decrease in its absorption intensity which may be explained by (4), a ground-state energy transfer from PFE molecules to BNDI (Figure 3(b)).

3.3. Characterization of Photodetectors. The maximum absorption intensity and quenching of photoluminescence is obtained from the film with $3: 1$ blend ratio of PFE:BNDI. Therefore, photodetector device structure of 


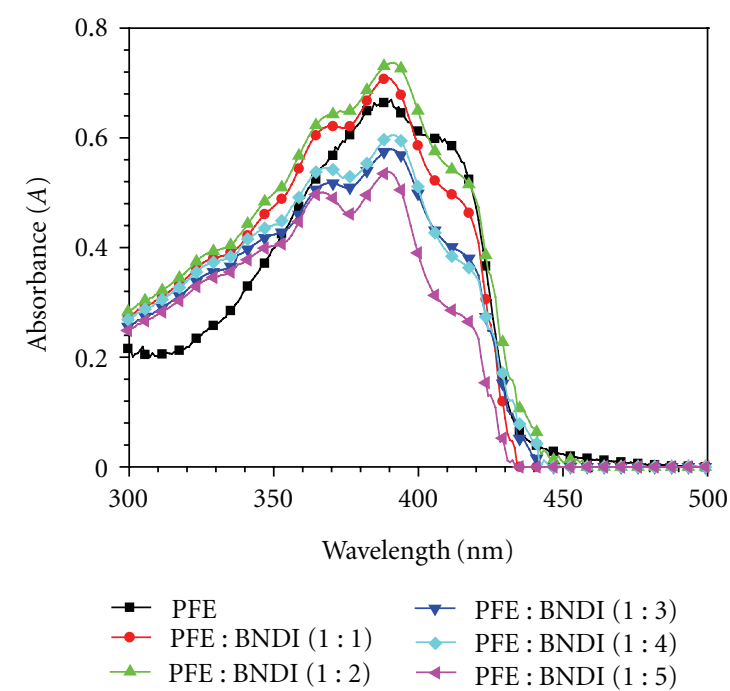

(a)

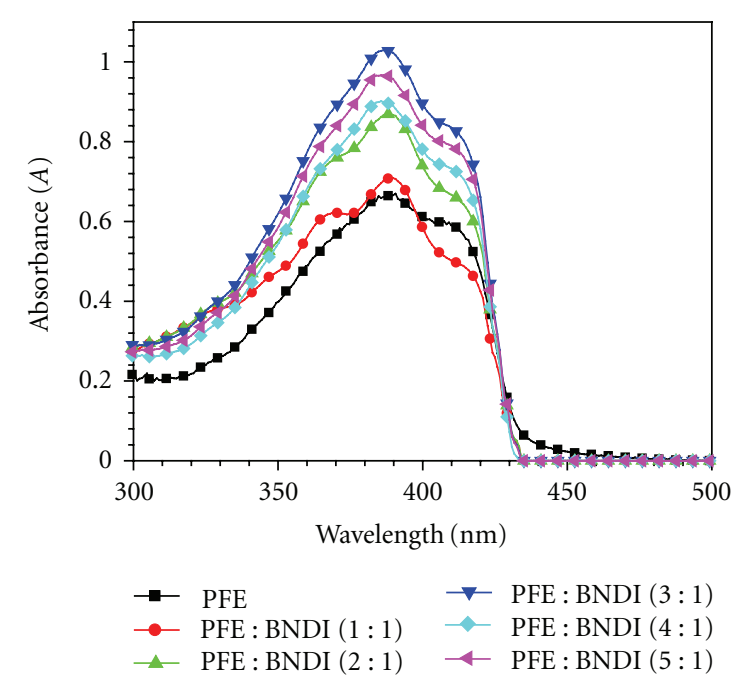

(c)

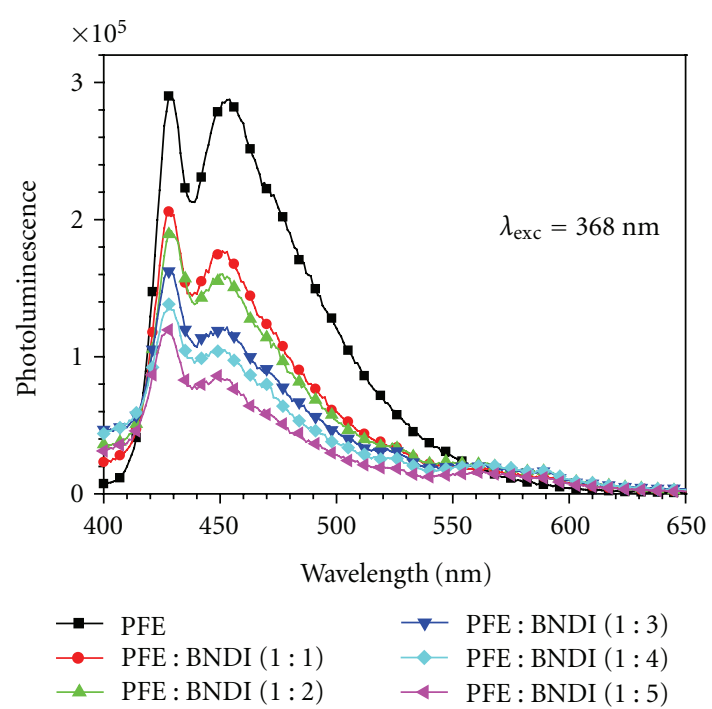

(b)

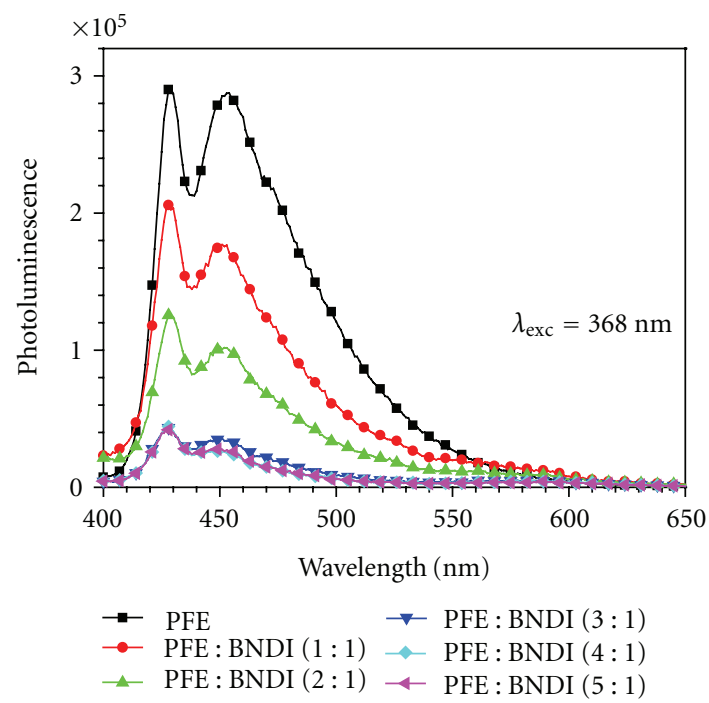

(d)

FIgURE 4: Absorption and photoluminescence spectra of (a) and (b) PFE: BNDI (1:1-5); (c) and (d) PFE: BNDI (1-5: 1).

ITO/ PEDOT:PSS/PFE:BNDI $(3: 1) / \mathrm{Al}$ is used to investigate the annealing temperature effect. Devices are illuminated at $368 \mathrm{~nm}$ through the ITO side, and current densities $(J$, $\mathrm{mA} / \mathrm{cm}^{2}$ ) are measured for the voltage range of $4-(-4) \mathrm{V}$. Spectral response of device is compared with absorbance of thin film in Figure 5. The shape of photoresponse curve is independent from the applied voltage and quite similar to the absorbance spectrum of thin film. The obtained $J$-versusvoltage curves are presented in Figure 6. It is worthy to note here that the devices prepared by using neat PFE or BNDI films gave very low $\left(J=47 \mu \mathrm{A} / \mathrm{cm}^{2}\right)$ or no responses at all (results not shown here).

ITO/PEDOT:PSS/PFE:BNDI $(3: 1) / \mathrm{Al}$ device prepared at RT gave a $J$ value of $0.19 \mathrm{~mA} / \mathrm{cm}^{2}$ at $-4 \mathrm{~V}$ under $1 \mathrm{~mW} / \mathrm{cm}^{2}$ illumination and as the annealing temperature is increased to $60^{\circ} \mathrm{C}$, this value reached its maximum, $0.41 \mathrm{~mA} / \mathrm{cm}^{2}$. Further increase in the annealing temperature that corresponds to $80^{\circ} \mathrm{C}$, and which is over the crystallization temperature of PFE, caused a dramatic decrease in the $J$ value, $0.14 \mathrm{~mA} / \mathrm{cm}^{2}$. The change in the morphology of the active layer by annealing temperature is monitored through phase-mode AFM studies. As it can be seen in Figure 7, all of the spin-coated films were rather rough with root-mean-square (RMS) values of $7.5-11.6 \mathrm{~nm}$. An obvious phase separation is obtained for the film annealed at $80^{\circ} \mathrm{C}$. The minimum RMS value was obtained with $60^{\circ} \mathrm{C}$ annealing. Further investigations on the reason of big difference obtained by annealing temperature change are performed by impedance spectroscopy as it is an ingenious tool for the explanation of electrical performances of photochemical molecular devices [27-31].

All of the impedance curves are in semicircular shape which point out a single relaxation time with a parallel 


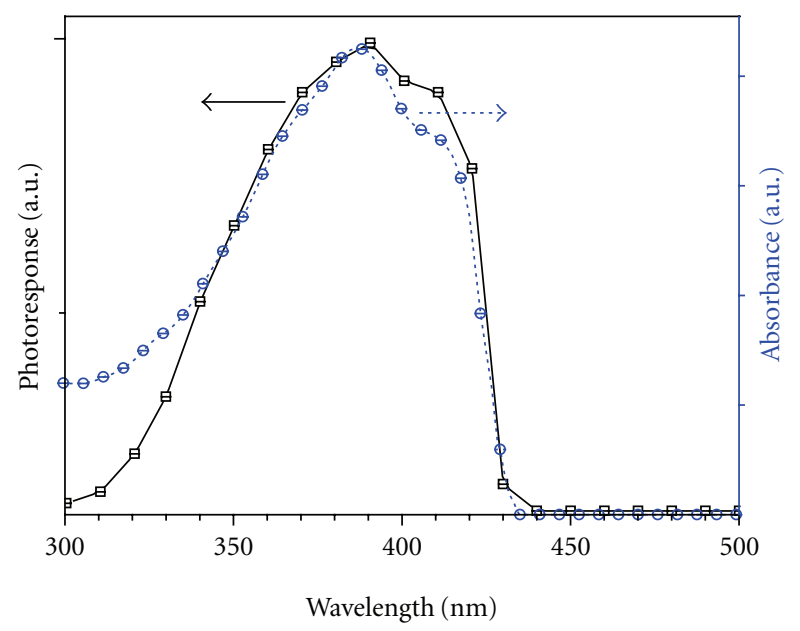

FIGURE 5: Photoresponse spectra of the device ITO/PEDOT:PSS/PFE:BNDI ( $3: 1) /$ Al illuminated from ITO electrode and absorbance spectra of Lam/PFE:BNDI $(3: 1)$ sample.

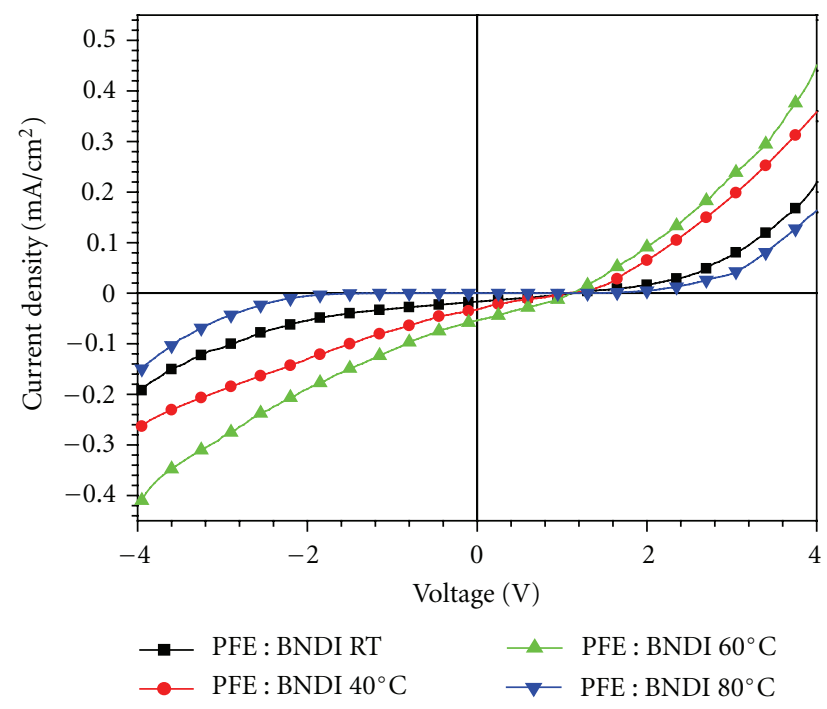

(a)

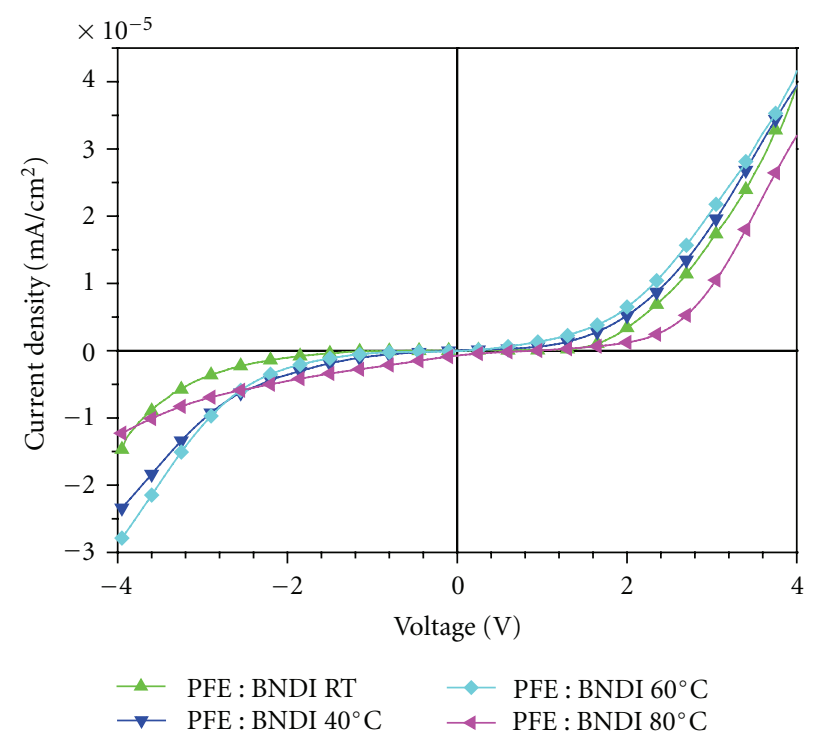

(b)

Figure 6: Current density-voltage curves of ITO/PEDOT:PSS/PFE:BNDI ( $3: 1)$ at RT and different annealing temperatures/Al (a) under $1 \mathrm{~mW} / \mathrm{cm}^{2}$ at $368 \mathrm{~nm}$ UV light and (b) in dark.

resistance-capacitance circuit. Therefore the impedance of devices is a function of resistance and capacitance [32]:

$$
\begin{aligned}
Z=Z^{\prime}-j Z^{\prime \prime}= & R_{s}+\left[\frac{R_{p}}{\left(1+\left(\omega R_{p} C_{p}\right)^{2}\right)}\right] \\
& -j\left[\frac{\omega R_{p}^{2} C_{p}}{\left(1+\left(\omega R_{p} C_{p}\right)^{2}\right)}\right],
\end{aligned}
$$

where $Z^{\prime}$ is the real and $Z^{\prime \prime}$ is the imaginary part of impedance, $R_{s}$ is the serial and $R_{p}$ is the parallel resistance, $C_{p}$ is the parallel capacitance, $\omega$ is the angular frequency $(2 \pi f)$, and $j$ is $(-1)^{1 / 2}$. The equivalent circuit model of the photodetector is given in Figure 8.

For all annealing temperatures diameter of semicircles are observed to decrease from dark to light and with applied voltage (Figure 9), due to a decrease of charge transfer resistance. The data obtained for the annealing temperature of $60^{\circ} \mathrm{C}$ is summarized in Figure 9(a). As-prepared device has a $R_{p}$ value of $61.8 \mathrm{k} \Omega$ that decreases to $19.5 \mathrm{k} \Omega$ at $4 \mathrm{~V}$ of reverse bias under $1 \mathrm{~mW} / \mathrm{cm}^{2}$ illumination intensity at $368 \mathrm{~nm}$. As is seen in Figure $6(\mathrm{a})$, up to $60^{\circ} \mathrm{C}$, shortcircuit current $\left(J_{\text {sc }}\right)$ values are increasing from $16 \mu \mathrm{A} / \mathrm{cm}^{2}$ to $53 \mu \mathrm{A} / \mathrm{cm}^{2}$, with annealing temperature and then a dramatic decrease is detected. Likewise, up to $60^{\circ} \mathrm{C}$, a decrease in the charge transfer resistance is obtained from the impedance 


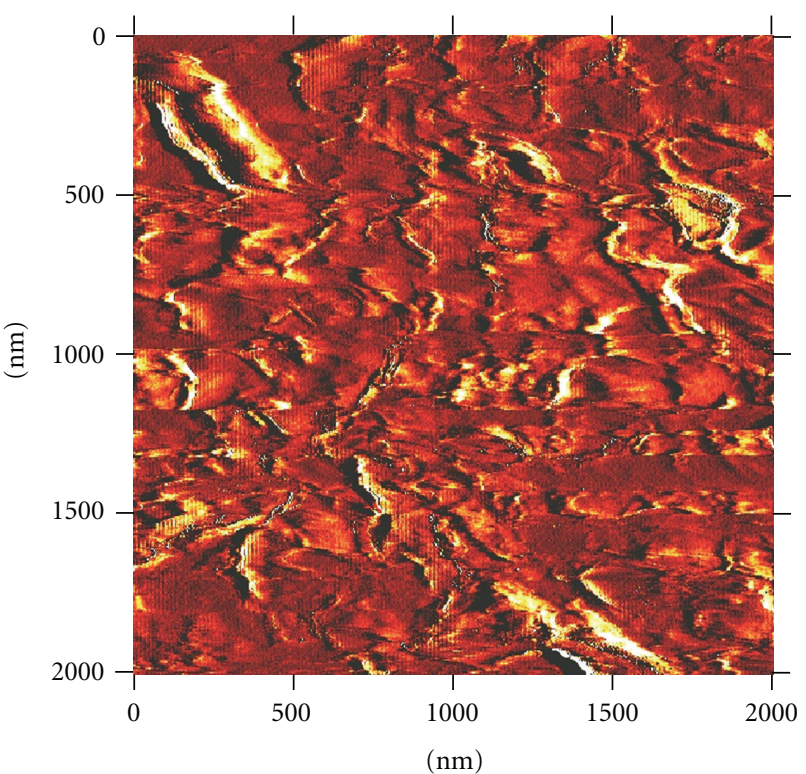

(a)

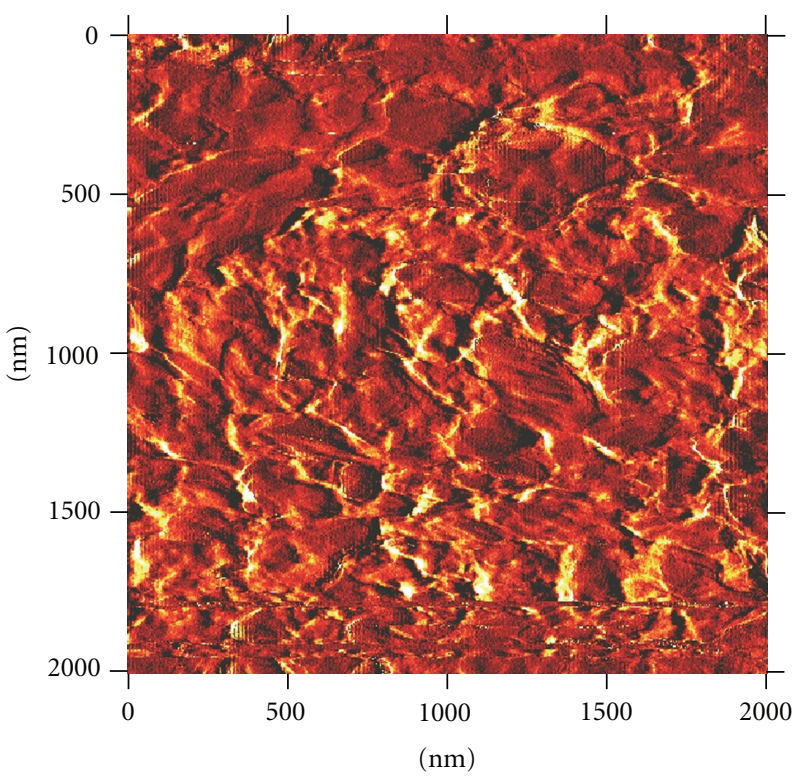

(c)

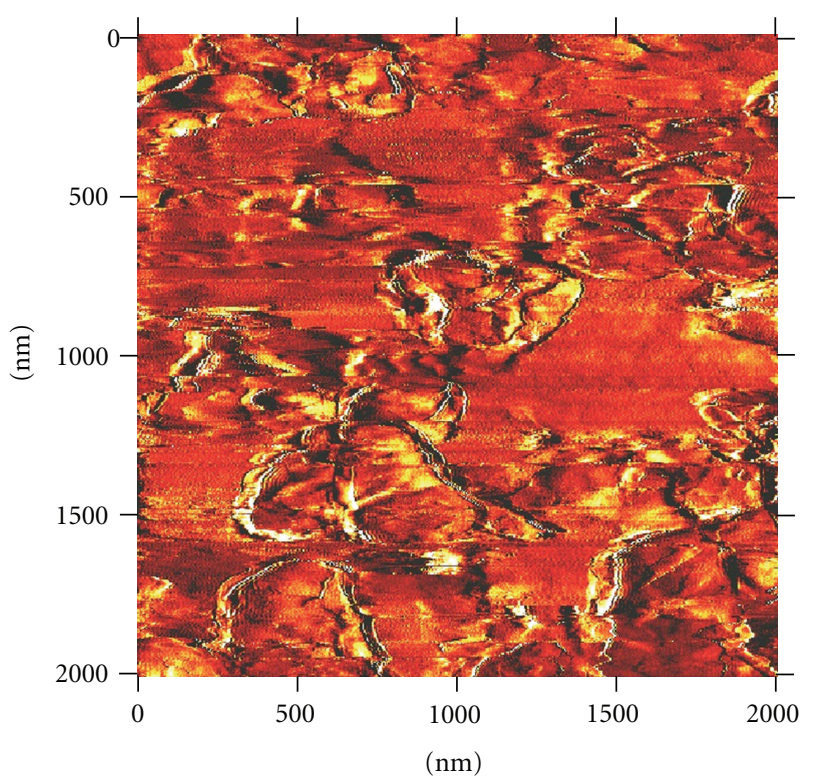

(b)

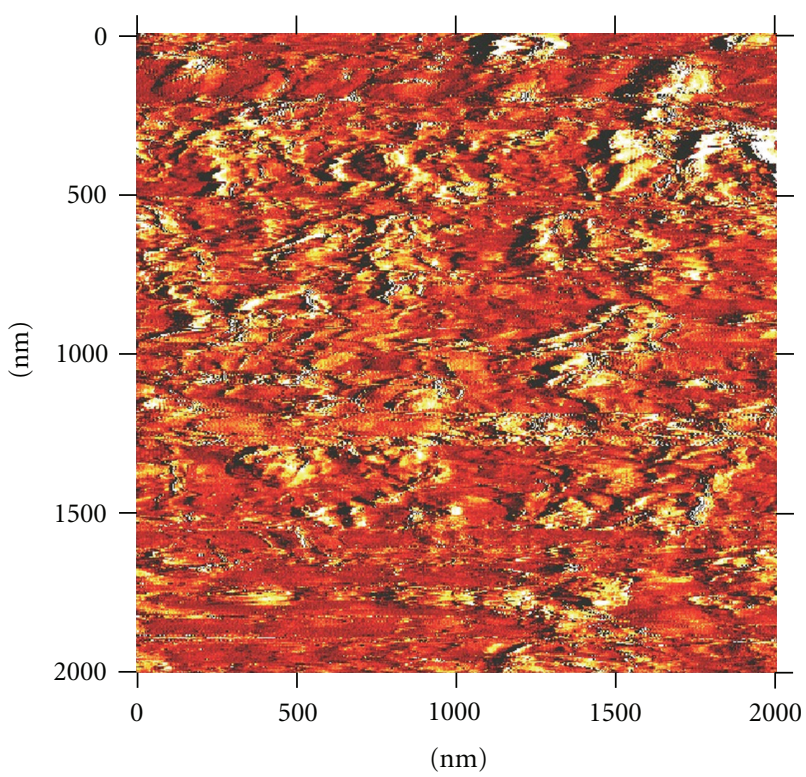

(d)

Figure 7: AFM phase images of PFE.BNDI (3:1) films annealed at different temperatures: (a) RT, RMS roughness: 11.2 , (b) $40^{\circ} \mathrm{C}$, RMS roughness: $10.4,(\mathrm{c}) 60^{\circ} \mathrm{C}$, RMS roughness: 7.5 , and (d) $80^{\circ} \mathrm{C}$, RMS roughness: 11.6.

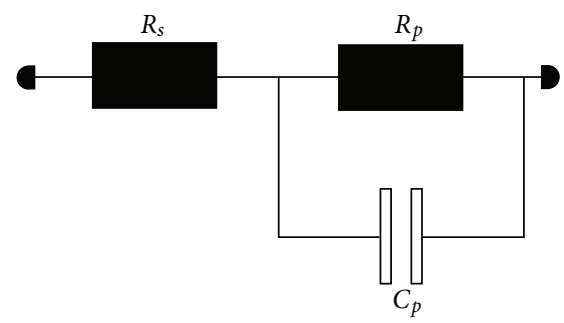

FIGURE 8: Equivalent circuit model of device. 


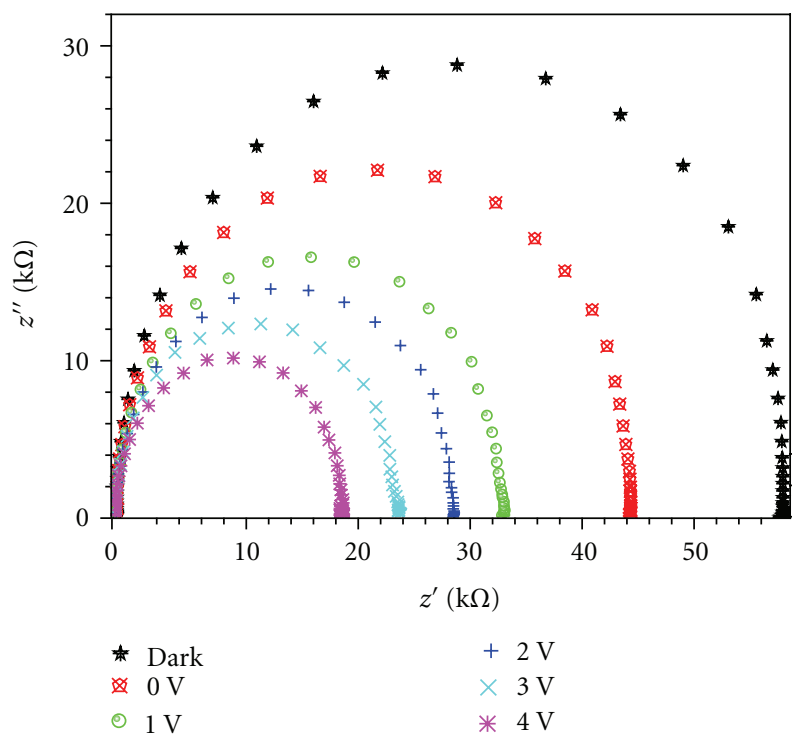

(a)

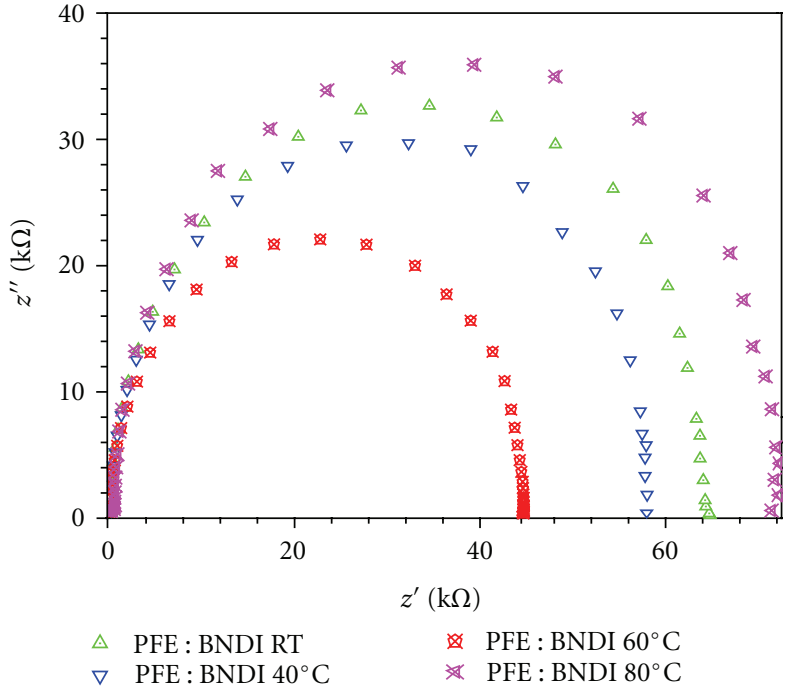

(b)

Figure 9: Complex impedance plot of ITO/PEDOT:PSS/PFE:BNDI $(3: 1)^{*} / \mathrm{Al}$, *: (a) $60^{\circ} \mathrm{C}$ in dark and under $1 \mathrm{~mW}^{*} \mathrm{~cm}^{2}$ at different reverse bias voltages and (b) at RT, $40^{\circ} \mathrm{C}, 60^{\circ} \mathrm{C}$, and $80^{\circ} \mathrm{C}$ under $1 \mathrm{~mW} / \mathrm{cm}^{2}$ at $368 \mathrm{~nm}\left(V_{\text {appl }}=0 \mathrm{~V}\right)$.

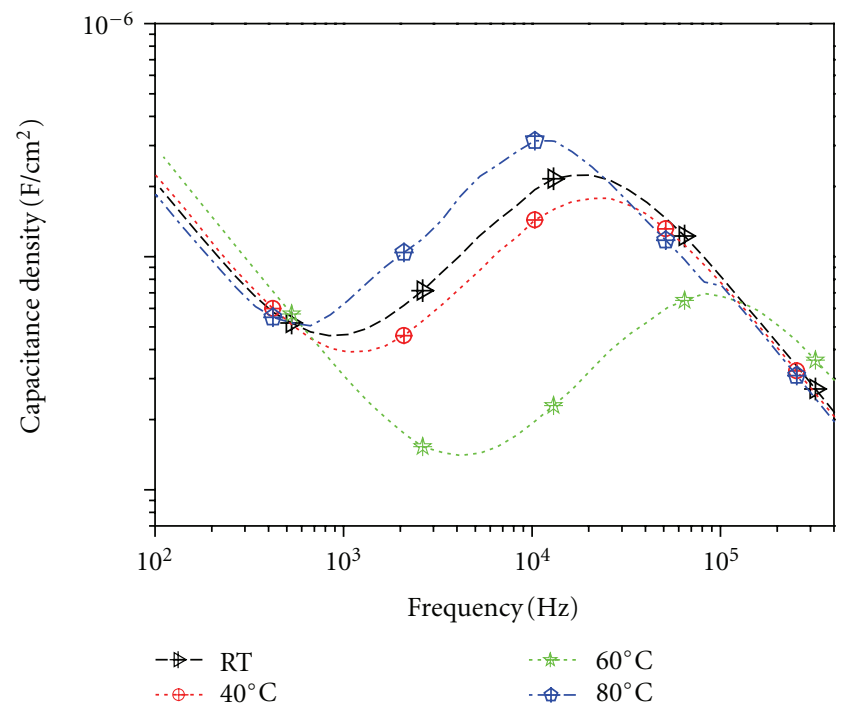

(a)

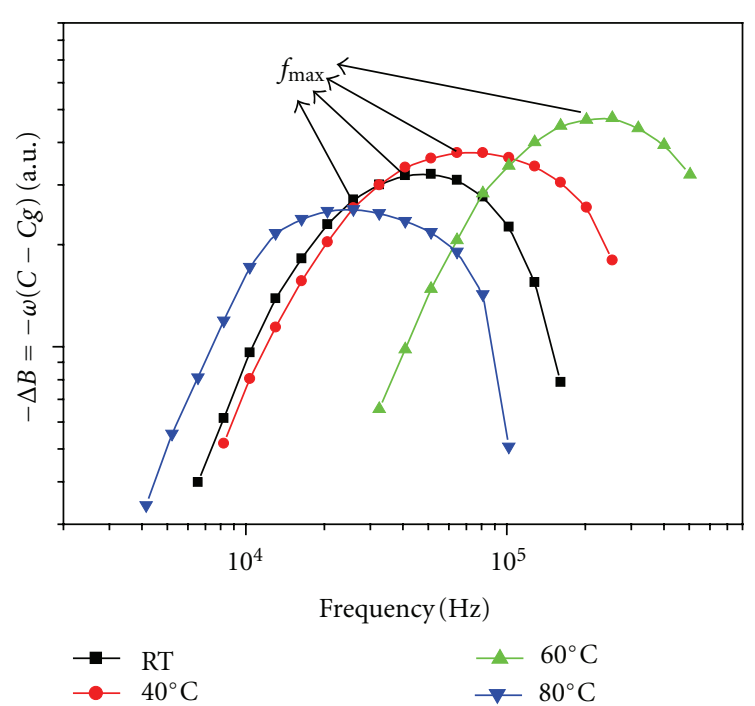

(b)

FIGURE 10: (a) Frequency spectra of capacitance and (b) negative differential susceptance for ITO/PEDOT:PSS/PFE:BNDI (3:1)/Al device at different temperatures under $1 \mathrm{~mW} / \mathrm{cm}^{2}$ at $368 \mathrm{~nm}$.

measurements. Increasing of photodetector performance and photoelectronic behavior with increasing annealing temperature (until $60^{\circ} \mathrm{C}$ ) may be explained by transit time $\left(\tau_{t}\right)$ reduction and mobility enhancement.

Capacitance density $\left(\mathrm{F} / \mathrm{cm}^{2}\right)$ can be described with $C=$ $1 / \omega Z^{\prime}$. The relaxation peaks of devices are clearly visible in the middle frequency region of capacitance density versus frequency curves given in Figure 10(a). $\tau_{t}$ is obtained by the negative differential susceptance $(-\Delta B)$ method that uses the capacitance minimum of $C$-frequency $(f)$ curve $[33,34]$ :

$$
-\Delta B=-\omega\left(C-C_{g}\right),
$$

where $C_{g}$ is the geometrical capacitance. From the frequency maxima of $-\Delta B$ versus $f$ spectra, $\tau_{t}$ can be evaluated through 


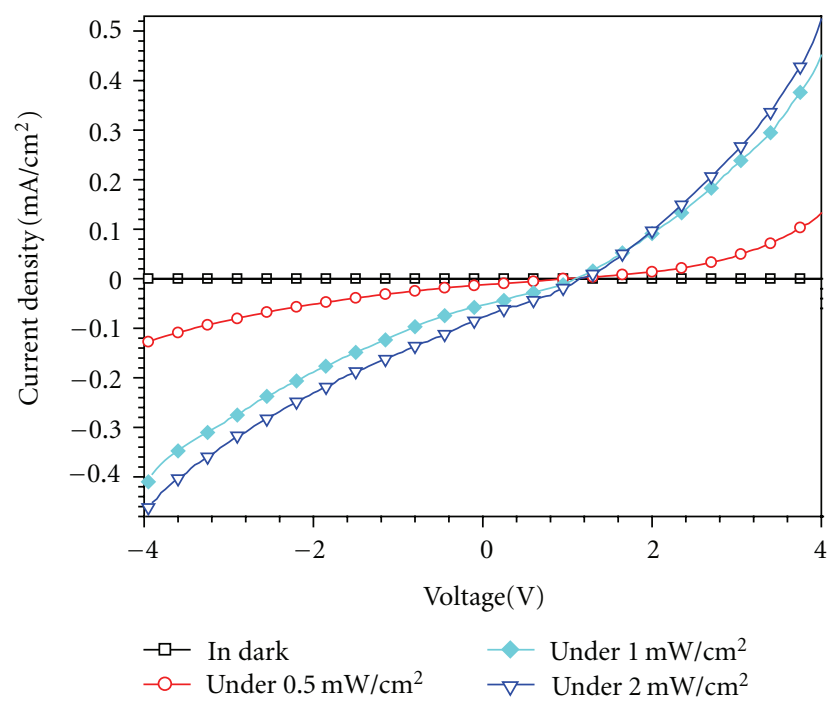

Figure 11: Current density-voltage curves of ITO/PEDOT: PSS/PFE:BNDI $(3: 1)$ at $60^{\circ} \mathrm{C}$ annealing temperature/Al under $0.5 \mathrm{~mW} / \mathrm{cm}^{2}$, $1 \mathrm{~mW} / \mathrm{cm}^{2}$ and $2 \mathrm{~mW} / \mathrm{cm}^{2}$ at $368 \mathrm{~nm}$ UV light.

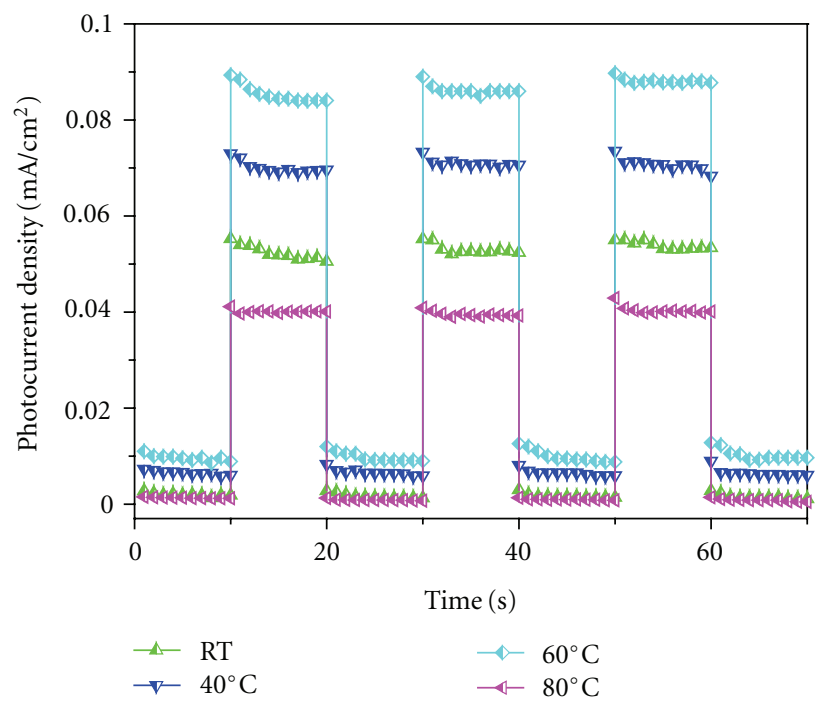

(a)

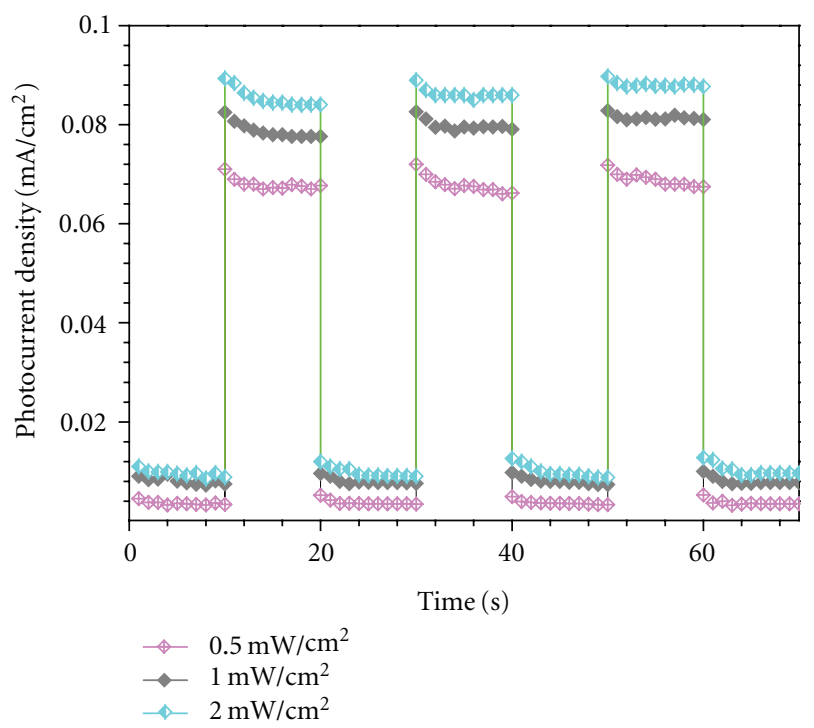

(b)

Figure 12: Photoresponse as a function of time at $0 \mathrm{~V}$ of ITO/PEDOT:PSS/PFE:BNDI $(3: 1)^{*} / \mathrm{Al} *$ : (a) annealed at RT, $40^{\circ} \mathrm{C}, 60^{\circ} \mathrm{C}$, and $80^{\circ} \mathrm{C}$ under $2 \mathrm{~mW} / \mathrm{cm}^{2}$ and (b) $60^{\circ} \mathrm{C}$-annealed device under $0.5 \mathrm{~mW} / \mathrm{cm}^{2}, 1 \mathrm{~mW} / \mathrm{cm}^{2}$, and $2 \mathrm{~mW} / \mathrm{cm}^{2}$ at $368 \mathrm{~nm} \mathrm{UV} \mathrm{light.}$

$f_{\max }=0.72 \tau_{t}^{-1}$ relation. However, charge carrier mobility can be determined by using

$$
\mu=\frac{4 L^{2}}{3 \tau_{t} V},
$$

where $L$ is the thickness of active layer and $V$ is potential. As shown in Figure 10(b), maximum $f_{\max }$ value is obtained with $60^{\circ} \mathrm{C}$ annealing that corresponds to minimum $\tau_{t}$ $\left(3.5 \times 10^{-6} \mathrm{~s}\right)$ and maximum total charge mobility $(2.5 \times$ $10^{-8} \mathrm{~cm}^{2} / \mathrm{Vs}$ ) (Table 2). The capacitance densities obtained for both low- and high-frequency regions are almost linear and independent from the annealing temperature (Figure $10(a))$.
Illumination-dependent photocurrent densities versus applied voltages are also investigated (Figure 11). Photocurrent and photovoltage are enhanced with increasing light intensity. The open-circuit photovoltage $\left(V_{\mathrm{oc}}\right)$ and $J_{\mathrm{sc}}$ values are increased from $0.9 \mathrm{~V}$ to $1.15 \mathrm{~V}$ and $12 \mu \mathrm{A} / \mathrm{cm}^{2}$ to $80 \mu \mathrm{A} / \mathrm{cm}^{2}$ when the incoming light intensity is increased from $0.5 \mathrm{~mW} / \mathrm{cm}^{2}$ to $2 \mathrm{~mW} / \mathrm{cm}^{2}$, respectively. Time-dependent photocurrent density characteristics of devices are shown in Figures 12(a) and 12(b). Photocurrent densities of devices are recorded for every 10 seconds when the UV light is on and off. For the first two UV-on cycles of the devices prepared at $\mathrm{RT}, 40^{\circ} \mathrm{C}$ and $60^{\circ} \mathrm{C}$, current leakages are observed for the first 2 seconds of operation which became saturated 
TABLE 2: Electrical parameters of blend devices.

\begin{tabular}{lcccl}
\hline & \multicolumn{4}{c}{ Annealing temperature $\left({ }^{\circ} \mathrm{C}\right)$} \\
\hline Parameters & RT & 40 & 60 & 80 \\
Responsivity $(\mathrm{mA} / \mathrm{W})$ & 192 & 263 & 410 & 149 \\
Mobility $\left(\times 10^{8}\right)\left(\mathrm{cm}^{2} / \mathrm{V} \cdot \mathrm{s}\right)$ & 0.59 & 0.94 & 2.5 & 0.29 \\
\hline
\end{tabular}

at the third cycle, and the slope of the photocurrent leakage is reduced with annealing temperature. This observation may be attributed to the enhanced charge balance in the device during the operation. However, the current leakage has started after the second UV-on UV-off cycle for the device that was annealed at $80^{\circ} \mathrm{C}$. Therefore, we may conclude that annealing temperatures applied over the crystallization temperature of the major component of the blend deteriorate not only the responsivity but also the long-term operation stability.

\section{Conclusion}

In this study, optical and electrical investigations of a PFE: BNDI-based UV photodetector is presented. It is worthy to note that the responsivity value of $410 \mathrm{~mA} / \mathrm{W}$ obtained with ITO/PEDOT:PSS/PFE:BNDI( $3: 1)$ annealed at $60^{\circ} \mathrm{C} / \mathrm{Al}$ device is higher than most of the already reported organic semiconductor-based UV photodetectors (Table 1). The enhancement can be attributed to the optimization of blend ratio by photoluminescence experiments and reduced resistance and increased mobility by annealing applied right under the crystallization temperature.

\section{Acknowledgments}

The authors acknowledge the project support funds of the Ege University (11GEE011) and the State Planning Organization of Turkey (Project Contract no. 11DPT001). They thank Saliha Ozdemir for the synthesis of BNDI.

\section{References}

[1] M. Razeghi and A. Rogalski, "Semiconductor ultraviolet detectors," Journal of Applied Physics, vol. 79, no. 10, pp. 74337473, 1996.

[2] Y. A. Goldberg, "Semiconductor near-ultraviolet photoelectronics," Semiconductor Science and Technology, vol. 14, no. 7, pp. R41-R60, 1999.

[3] E. Monroy, F. Omnès, and F. Calle, "Wide-bandgap semiconductor ultraviolet photodetectors," Semiconductor Science and Technology, vol. 18, no. 4, pp. R33-R51, 2003.

[4] T. Hamasaki, T. Morimune, H. Kajii et al., "Fabrication and characteristics of polyfluorene based organic photodetectors using fullerene derivatives," Thin Solid Films, vol. 518, no. 2, pp. 548-550, 2009.

[5] Z. Su, W. Li, B. Chu et al., "High response organic ultraviolet photodetector based on blend of $4,4^{\prime}, 4^{\prime \prime}$-tri-(2methylphenyl phenylamino) triphenylaine and tris-(8-hydroxyquinoline) gallium," Applied Physics Letters, vol. 93, no. 10, Article ID 103309, 2008.
[6] G. Zhang, W. Li, B. Chu et al., "Highly efficient photovoltaic diode based organic ultraviolet photodetector and the strong electroluminescence resulting from pure exciplex emission," Organic Electronics, vol. 10, no. 2, pp. 352-356, 2009.

[7] H. G. Li, G. Wu, H. Z. Chen, and M. Wang, "Solution-processed organic UV photodetectors based on polyfluorene and naphthalenediimide," Current Applied Physics, vol. 11, no. 3, pp. 750-754, 2011.

[8] Y. Han, G. Wu, M. Wang, and H. Chen, "High efficient UV-A photodetectors based on monodispersed ligand-capped $\mathrm{TiO}_{2}$ nanocrystals and polyfluorene hybrids," Polymer, vol. 51, no. 16, pp. 3736-3743, 2010.

[9] Y.-G. Han and L.-L. Wu, "Influence of surface ligand on ultraviolet photodetection property of $\mathrm{TiO}_{2}$ nanocrystal/polymer hybrids," Journal of Electronic Materials, vol. 40, no. 10, pp. 2147-2151, 2011.

[10] F. Ali, N. Periasamy, M. P. Patankar, and K. L. Narasimhan, "Integrated organic blue LED and visible-blind UV photodetector," Journal of Physical Chemistry C, vol. 115, no. 5, pp. 2462-2469, 2011.

[11] H. G. Li, G. Wu, M. M. Shi, H. Z. Chen, and M. Wang, "Synthesis of solution processable ultraviolet sensitive organic molecules and their application in hybrid UV photodetector," Synthetic Metals, vol. 160, no. 15-16, pp. 1648-1653, 2010.

[12] F. Yan, H. Liu, W. Li et al., "Double wavelength ultraviolet light sensitive organic photodetector," Applied Physics Letters, vol. 95, no. 25, Article ID 253308, 2009.

[13] L. Wang, D. Zhao, Z. Su et al., "High spectrum selectivity organic/inorganic hybrid visible-blind ultraviolet photodetector based on $\mathrm{ZnO}$ nanorods," Organic Electronics, vol. 11, no. 7, pp. 1318-1322, 2010.

[14] Y. Han, G. Wu, M. Wang, and H. Chen, "Hybrid ultraviolet photodetectors with high photosensitivity based on $\mathrm{TiO}_{2}$ nanorods array and polyfluorene," Applied Surface Science, vol. 256, no. 5, pp. 1530-1533, 2009.

[15] H. G. Li, G. Wu, H. Z. Chen, and M. Wang, "Spectral response tuning and realization of quasi-solar-blind detection in organic ultraviolet photodetectors," Organic Electronics, vol. 12, no. 1, pp. 70-77, 2011.

[16] J. B. Wang, W. L. Li, B. Chu et al., "Visible-blind ultraviolet photo-detector using tris-(8-hydroxyquinoline) rare earth as acceptors and the effects of the bulk and interfacial exciplex emissions on the photo-responsivity," Organic Electronics, vol. 11, no. 7, pp. 1301-1306, 2010.

[17] C. Karapire, Photophysical and photoelectrochemical studies of selected photosensitizers, Ph.D. thesis, 405.02.01, 2003.

[18] D. Shukla, S. F. Nelson, D. C. Freeman et al., "Thin-film morphology control in naphthalene-diimide-based semiconductors: high mobility n-type semiconductor for organic thinfilm transistors," Chemistry of Materials, vol. 20, no. 24, pp. 7486-7491, 2008.

[19] T. B. Singh, S. Erten, S. Günes et al., "Soluble derivatives of perylene and naphthalenediimide for n-channel organic fieldeffect transistors," Organic Electronics, vol. 7, no. 6, pp. 480489, 2006.

[20] S. Alp, S. Erten, C. Karapire, B. Köz, A. O. Doroshenko, and S. Içli, "Photoinduced energy-electron transfer studies with naphthalenediimides," Journal of Photochemistry and Photobiology A, vol. 135, no. 2-3, pp. 103-110, 2000.

[21] D. Buckland, S. V. Bhosale, and S. J. Langford, "A chemodosimer based on a core-substituted napthalene diimide for fluoride ion detection," Tetrahedron Letters, vol. 52, pp. 19901992, 2011. 
[22] M. Redecker, D. D. C. Bradley, M. Inbasekaran, and E. P. Woo, "Nondispersive hole transport in an electroluminescent polyfluorene," Applied Physics Letters, vol. 73, no. 11, pp. 15651567, 1998.

[23] F. Tinti, S. E. Debebe, W. Mammo, T. Yohannes, and N. Camaioni, "Temperature and electric field dependent hole mobility in a polyfluorene copolymer," Synthetic Metals, vol. 161, pp. 794-798, 2011.

[24] C. P. Liu and Y. T. Hung, "The effect of thermal annealing and evaporating vacuum level on the performance of a polyfluorene-based polymer light emitting diode," Thin Solid Films, vol. 492, no. 1-2, pp. 269-274, 2005.

[25] W. Huang, J. Peng, and L. Wang, "Investigation of annealing effects on microstructure of hybrid nanocrystal-polymer solar cells by impedance spectroscopy," Synthetic Metals, vol. 160, no. 5-6, pp. 445-449, 2010.

[26] M. Kus, Ö. Hakli, C. Zafer et al., "Optical and electrochemical properties of polyether derivatives of perylenediimides adsorbed on nanocrystalline metal oxide films," Organic Electronics, vol. 9, no. 5, pp. 757-766, 2008.

[27] N. H. Al-Hardan, M. J. Abdullah, H. Ahmad, A. A. Aziz, and L. Y. Low, "Investigation on UV photodetector behavior of RF-sputtered $\mathrm{ZnO}$ by impedance spectroscopy," Solid-State Electronics, vol. 55, no. 1, pp. 59-63, 2011.

[28] Z. G. Shao, I. M. Hsing, H. Zhang, and B. Yi, "Influence of anode diffusion layer on the performance of a liquid feed direct methanol fuel cell by AC impedance spectroscopy," International Journal of Energy Research, vol. 30, no. 14, pp. 1216-1227, 2006.

[29] J. Bisquert, G. Garcia-Belmonte, Á. Pitarch, and H. J. Bolink, "Negative capacitance caused by electron injection through interfacial states in organic light-emitting diodes," Chemical Physics Letters, vol. 422, no. 1-3, pp. 184-191, 2006.

[30] C. Zafer, K. Ocakoglu, C. Ozsoy, and S. Icli, "Dicationic bisimidazolium molten salts for efficient dye sensitized solar cells: synthesis and photovoltaic properties," Electrochimica Acta, vol. 54, no. 24, pp. 5709-5714, 2009.

[31] L. Pereira, L. Raniero, P. Barquinha, E. Fortunato, and R. Martins, "Impedance study of the electrical properties of polySi thin film transistors," Journal of Non-Crystalline Solids, vol. 352, no. 9-20, pp. 1737-1740, 2006.

[32] J. Huang, Z. Xu, S. Zhao et al., "Study on carrier mobility measurement using electroluminescence in frequency domain and electrochemical impedance spectroscopy," Measurement, vol. 43, no. 3, pp. 295-298, 2010.

[33] H. C. F. Martens, W. F. Pasveer, H. B. Brom, J. N. Huiberts, and P. W. M. Blom, "Crossover from space-charge-limited to recombination-limited transport in polymer light-emitting diodes," Physical Review B, vol. 63, no. 12, Article ID 125328, pp. 1253281-1253287, 2001.

[34] T. Okachi, T. Nagase, T. Kobayashi, and H. Naito, "Influence of injection barrier on the determination of charge-carrier mobility in organic light-emitting diodes by impedance spectroscopy," Thin Solid Films, vol. 517, no. 4, pp. 1331-1334, 2008. 


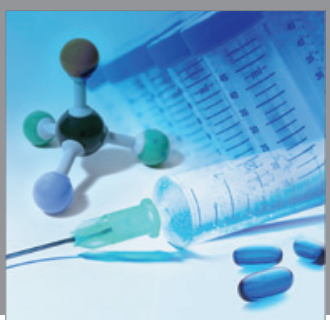

International Journal of

Medicinal Chemistry

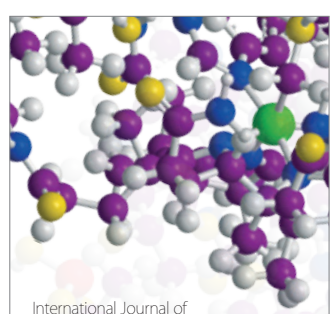

Carbohydrate Chemistry

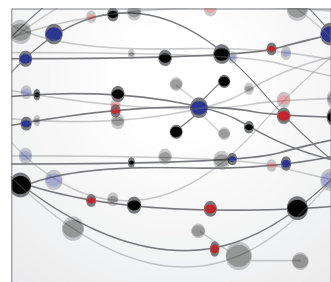

The Scientific World Journal
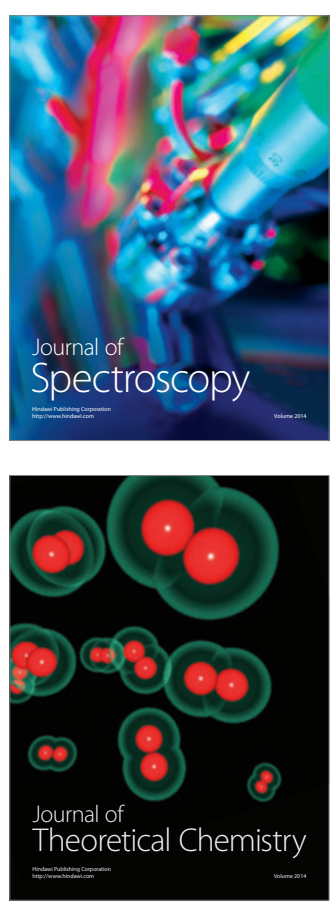
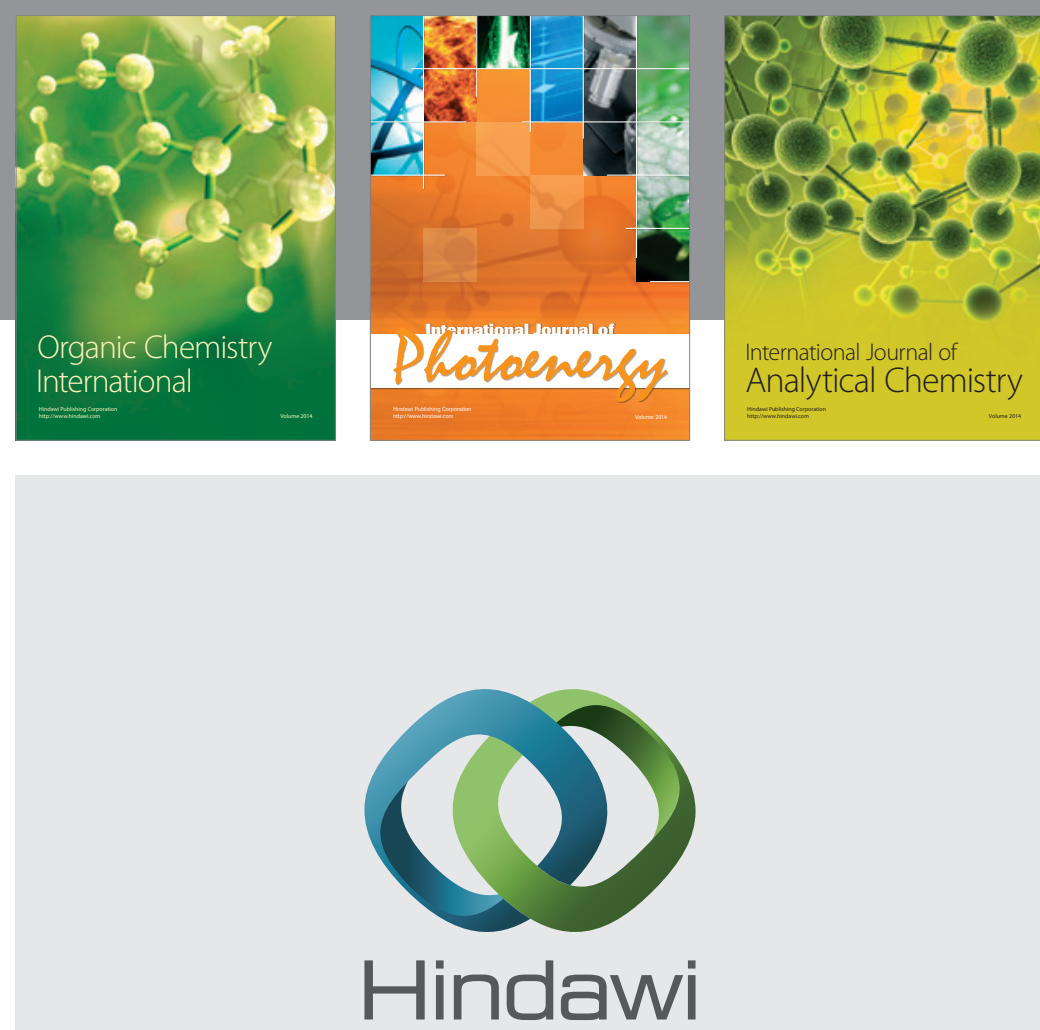

Submit your manuscripts at

http://www.hindawi.com
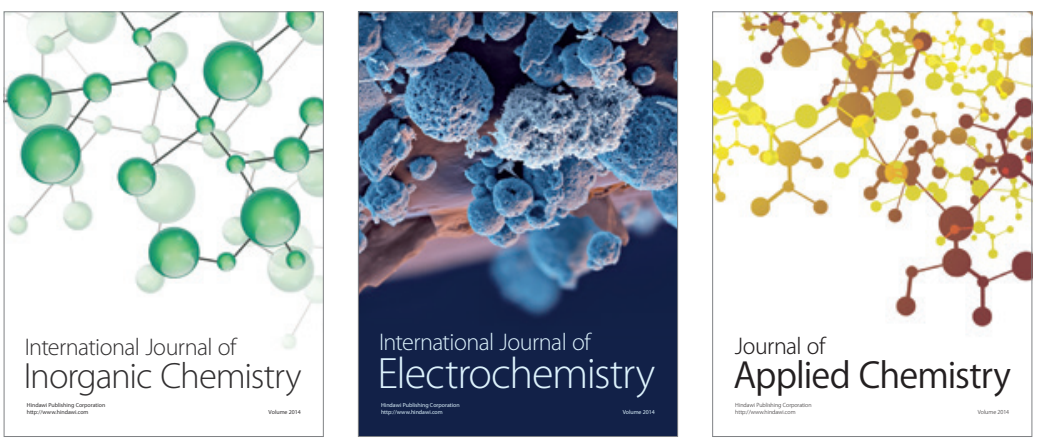

Journal of

Applied Chemistry
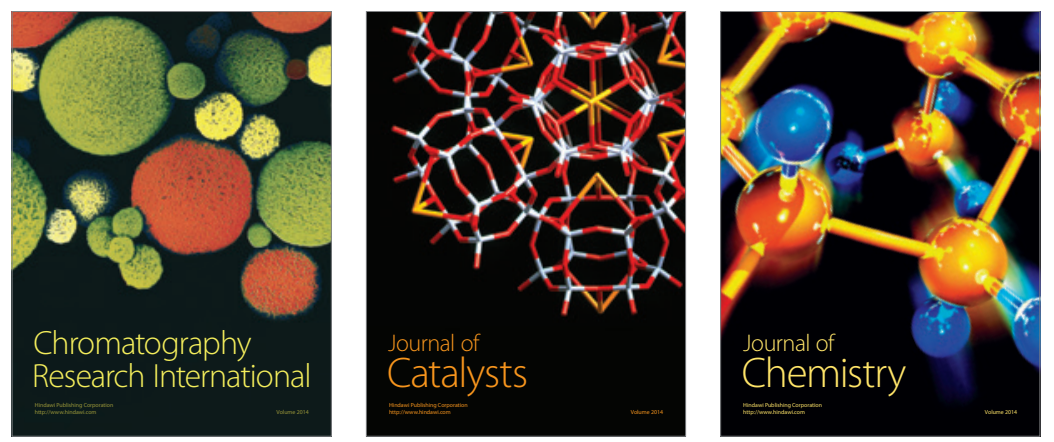
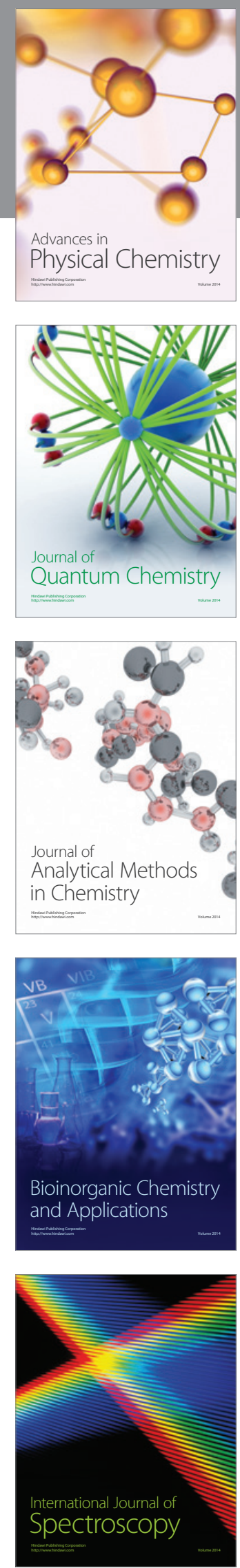